\title{
Research on Models of Individual Accounts in Pension Insurance
}

\author{
Chen Zimin ${ }^{1, a}$ Zhuyin Liang ${ }^{2, b}$ Qian Ailin ${ }^{1, c}$ He Guozhong ${ }^{3, d, ~ * ~}$ \\ 1 Hubei University of Science and Technology, China \\ 2 Finance Bureau of Xianning City, Hubei Province, China \\ 3 * School of Public Health, Kunming Medical University, China, Corresponding Author \\ a449138671@qq.coml, b1125166281@qq.com, cjunren751113@126.com, d273591204@qq.com
}

Keywords: pension insurance, individual accounts, Non-financial Defined Contribution (NDC).

\begin{abstract}
Objective: To conduct a Comparative Analysis of three models of individual pension accounts from the perspective of management, efficiency, security level and other aspects. Methods: Matlab modeling is employed for empirical quantitative analysis of insurance fund operation the three different models. Results: (1) In terms of total value of pension, replacement rate and other indicators, the security level of $\mathrm{NDC} \approx \mathrm{FDC}>$ real accounts; (2) In terms of longitudinal connotative rate of return, NDC $>$ FDC $>$ real accounts; (3) compared with the Real Account, NDC has the managerial advantages: promote the escalation of social pooling level, inspire employees' enthusiasm for contributions and extension of payment periods to achieve delayed retirement, eliminate investment bottlenecks, and ease the financial pressure for current payment. Conclusion: (1) different models of individual accounts will not change the contributor's rights and interests. (2) From the perspective of security level, management, efficiency, and China's actual situation of individual accounts, the hybrid SP\& IPA system based on NDC funding model is a rational choice suitable for China's pension reform.
\end{abstract}

\section{Introduction}

Pension insurance is an important part of the social security system. China's current pension system was implemented as from 1972, and further improved in 2005, featuring the integration of social pooling and individual accounts. This Model albeit played an ideal role in the period of economic reform, came across huge deficit in pension funds during concrete operation. To protect employees' basic rights and interests while maintaining operational security of funds, decision-making departments continued to explore new models, wherein controversies arise around the selection of Non-Financial Defined Contribution (NDC) or Financial Defined Contribution (FDC) for individual accounts in specific implementation process[1]. Since 2014, the relevant department heads proposed in the "China Pension Report 2014" launching ceremony that, it has been unsustainable to financially define individual account, NDC is a selectable model for next step reform of pension insurance system. Resorting to empirical data of a Midwest City in Hubei Province, this Paper compares the pros and cons of NDC, FDC and current accounts, to provide evidence for reform of pension models.

\section{Data sources and Methods}

2004--2014 Survey data in six counties of a Midwest City. Topics include demographic, socio-economic information, constitution of employees in pension insurance, insurance revenue and expenditure and other related information.

Matlab software is used for modeling \& analysis. 


\section{Results and Analysis}

According to China's current system, individual accounts contribution rate is $8 \%$ of wages, social pooling accounts for $20 \%$ of wages, wherein personal payments partially go into individual accounts; post-retirement-life-expectancy at retirement age of 60 is 27 years, individual account pension replacement rate target is $20 \%$. Non-financial Defined Contribution (NDC), Financial Defined Contribution (FDC), and the current account all recorded contributions, investment income and expense deductions, upon retirement, account balance shall be transferred into life annuity payment. The analysis shall compare the pension replacement rate, total value, distribution of connotative rate of return, and pension funding ratio (the proportion of liabilities covered by assets) of three models under identical average contribution rate.

\subsection{Individual account Income}

To facilitate calculation, we assume enrollees individual accounts' payment is once a year at the beginning of each year, with $\mathrm{C}$ ratio of wages, annual wages of year $\mathrm{k}$ is wk, and the payment is uninterrupted before retirement, payment period is $\mathrm{T} 1$, year $\mathrm{K}$ 's interest rate is $\mathrm{i}$, management costs are charged according to the proportion of the asset value, where $\mathrm{C}=8 \%, \mathrm{f}=0.04 \%[2]$, contributions years is 15 , the accumulated amount of individual accounts $\mathrm{T}$ years before retirement is:

$$
A_{t}=c \sum^{T_{1}} w_{t-n}(1-f)^{n} \prod^{n}\left(1+i_{t-m}\right)
$$

The three models have identical Equation for calculation of accumulated amount of individual accounts, the difference lies in different interest rates, wherein the NDC interest rate denotes its endogenous growth rate. NDC Endogenous growth rate = wages growth rate + labor population growth rate. Wage growth rate is subject to 3 cases: average wage growth rate, total wage-for-payment growth rate, and GDP growth. Since GDP can better reflect the level of economic development of a region, the calculation of endogenous growth is GDP-based. As can be seen from Table 1, the local GDP growth presented a lognormal distribution, with 2004--2014 average of $16.29 \%$, but the regional GDP in 2006 - 2012 is in rapid rise, while the growth rate declined obviously in recent years, taking into account the national economies' rapid development in the past 20 years, and the slow-down of future economy and wage growth, we did not use the World Bank GDP growth forecast for analysis, but rather, the $8 \%$ endogenous growth rate predicted by Zheng BingWen et al, which is slightly lower the 2014 GDP growth rate in Xianning City. For labor force growth rate, we take \%, a forecast result of Mazhong Dong[3,4].

Current model's individual account nominal interest rate is the one-year bank deposit interest rate, in view of the slightly different interest rates of different banks and time, for convenience of calculation, we take the rate of $3 \%$.

The calculation of FDC Account's interest rate is based on Wang Xiaojun's forecast of 7.33\%.

Table 1 Logarithmic descriptive statistics of 2001--2014 employee wage growth rate

\begin{tabular}{|l|l|l|l|l|}
\hline & Min & Max & Average & Standard deviation \\
\hline Wage growth log & 2.11 & 3.14 & 2.4945 & .38312 \\
\hline GDP Growth Rate & 2.03 & 3.30 & 2.7906 & .43885 \\
\hline
\end{tabular}

According to Equation (1) and different account interest rates data, the calculation of accumulated amount of pre-retirement pension in individual accounts shows that: according to the $8 \%$ payroll contribution rate, the $8 \%$ payroll contribution rate, the relevant interest rate and GDP growth rate, during the 15 years from 2015 to 2029 , each enrollee shall actually pay a total amount of 73,641 yuan for individual account, the accumulated amount of pre-retirement NDC is calculated up to 133,527 yuan, and 91,184 yuan for while the real accounts, 126,717 yuan for FDC, NDC is slightly higher than FDC, while the Real Account accumulated amount is far less than that of the other two Accounts.

The calculation shows that the principal influence factor of pension accumulation is the actual amount of contribution and endogenous growth (rate), while the management costs' impact upon final accumulated amount is almost negligible. 


\section{2 forecasts of individual account expenditure}

In the collection phase, assuming that the pension is collected annually at the beginning of each year until death, suppose years of collection as T2, which is tentatively set as 15 years, the first year collection amount is $\mathrm{B}=$ pre-retirement accumulated pension / 15; Pension Adjustment Index is $\mathrm{g}$, pensions should be adjusted according to the level of the CPI rise, to ensure the actual purchasing power of pensions, and avoid damage to the interests of employees. From 2004 to 2014, the survey area's CPI growth is relatively stable, with an average 3.3\% rise over the previous year, so the pension adjustment factor is set at 3.3; the discount rate is $\mathrm{j}$, thence the following computations shall be made, still according to the interest rates of the above three models, namely $7.33 \%$ for FDC, 3\% for real accounts, and GDP+ labor force growth rate forecast for NDC.

\subsubsection{Replacement Rate}

Based on the above indicators, the present value of pension at retirement time $t$ is derived:

$$
s_{t}=B \sum_{m=0}^{T_{2}-1}\left(\frac{1+g}{1+j}\right)^{m}
$$

Pension replacement rate denotes the percentage of retirement-year collected pension in the

wages of the previous year. $R R_{t}=\frac{B}{w t-1} * 100 \%$

\subsubsection{The total value of pensions}

The total value of pension represents the present value of future pension upon retirement, in order to eliminate price effects, a proportion of the wages of the year before retirement is introduced.

$$
W R_{t}=\frac{S_{T}}{w t-1}
$$

\subsubsection{Longitudinal connotative rate of return}

Longitudinal connotative rate of return refers to the ROR rendering the equation of payment value and collected value, which is to satisfy the IRR in following Equation.

$$
\sum^{T_{2}} \frac{C w_{t-n}}{(1+1 R R)^{T_{2}-n}}=\sum^{T_{2}} \frac{B(1+g)^{n-1}}{(1+1 R R)^{T_{2}+n+1}}
$$

When PRt is greater than or equal to 1, it indicates that the pension plan has achieved or exceeded the desired objectives, otherwise the desired objectives are not achieved. Pension Ratio analysis also manifested the same results as in replacement rate analysis. Under the premises of 15 contribution years, pension adjustment factor= average CPI level in the area, and interest rates equal to the above calculations, NDC and FDC accounts all exceeded the preset goal of benefits, but the current model did not meet expectations.

\subsubsection{Forecasts of pension expenditure}

According to the Equation (2), as well as the 2029 wage level predicted above, the present value St and replacement rate RRt of the three accounts upon retirement are derived in Table 2:

Table 2 comparison of three models' pension replacement rate and total value

\begin{tabular}{|l|c|c|c|}
\hline & NDC & FDC & Real Account \\
\hline Replacement rate \% & 10.80 & 10.24 & 7.4 \\
\hline Total value of pensions & 1.13 & 1.12 & 1.06 \\
\hline Longitudinal Connotative ROR & 0.050 & 0.047 & 0.024 \\
\hline Pension funding ratio & 1.34 & 1.29 & 0.98 \\
\hline
\end{tabular}

As shown by the calculation results, with 15 contribution years, the amount of individual accounts in three models are all serious deficient, and far less than the $20 \%$ standard of replacement rate, especially real account only reached a replacement rate of $7.4 \%$, resulting in pension collection's inevitable diversion of funds in the pooling account or the Government's further investment. Therefore, the executive power for current 15-year contribution policy is inevitably insufficient, 
requiring the Government's further investment, extension of pension payment period, or postponement of retirement, and other measures.

The total value of pensions shows that NDC and FDC's total value are both substantial and not very different, as for real accounts, due to CPI $>$ bank interest rates, suffered serious devaluation. As can be seen from the longitudinal connotative rate of return, NDC's ROR is higher than that of the other two accounts, wherein the current account has the lowest ROR, which is even lower than bank interest rates. Pension ratio shows that real account can not achieve policy objectives, while NCD has the best achievement ability.

\subsection{Comparison of government investments}

The above analysis shows that individual account can only achieve a replacement rate of $10.8 \%$ at best, which is well below the national policy objectives of $20 \%$, indicating that in accordance with the existing contribution years, it is impossible to achieve the policy objectives, this will only result in a growing funding gap, forming a huge vicious circle. To achieve the policy objectives, if the payment period cannot be extended, the only alternative is the government's further investment.

Table 3 prediction of financial subsidies

\begin{tabular}{|l|c|c|c|c|}
\hline & & NDC & FDC & Real Account \\
\hline \multirow{3}{*}{$\begin{array}{l}\text { Individual } \\
\text { account }\end{array}$} & Actual replacement rate & 10.80 & 10.24 & 7.4 \\
\cline { 2 - 5 } & Target replacement rate & 9.2 & 9.76 & 12.6 \\
\cline { 2 - 5 } & Financial subsidy /per capita GDP \% & 3.24 & 3.43 & 4.43 \\
\hline \multirow{2}{*}{$\begin{array}{l}\text { Social pooling } \\
\text { account }\end{array}$} & Actual replacement rate & 27 & 25.6 & 18.5 \\
\cline { 2 - 5 } & Target replacement rate & 13 & 14.4 & 21.5 \\
\cline { 2 - 5 } & Financial subsidy/per capita GDP \% & 4.57 & 5.07 & 7.56 \\
\hline Total subsidy & Financial subsidy/GDP\% & 7.81 & 8.50 & 11.99 \\
\hline
\end{tabular}

Pooling account's actual replacement rate $=20 / 8 *$ individual account's actual replacement rate

Financial subsidies' share $\%$ in per capita GDP $=$ (rate difference * number of insured employees) / total number of local population

In 2014, pension expenditure in the region is $42.08 \%$ of wage level in 2013, and the actual government investment in Pension Insurance accounts for 5.03\% of GDP. In accordance with the $60 \%$ policy target, the government needs to put in $7.18 \%$ of GDP, this rate is not much different with NDC's $7.81 \%$ share in GDP, but government investment shall be more than double to achieve policy goals for real accounts, pension insurance will become an impossible burden for the Government!

The above analysis of social pooling funding assumed that the capital ROR equals to that of the individual accounts, in fact, if the social pooling funding is PAYG-based, there shall be no ROR at all, the funding gap will be even greater, and the government shall invested more!

\section{Discussion and Analysis}

The above analysis shows that: for three individual accounts, under the same contribution rate, NDC can achieve higher pension replacement rate, total value and connotative rate of return with less risks. In terms of pension benefits, FDC account is just slightly lower than NDC, while the benefits of both were far higher than those of the current account. But from a managerial perspective, NDC is superior over FDC. Hence NDC is the better choice.

\subsection{Demerits of current account model and FDC model}

Theoretically, china's mixed pension model of PAYG+accumulation system, established in 1997, is feasible, where the "basic pension" reflects a "mutual aid society" principle, and "individual accounts" fully reflected the "self-protection" principle, the mixed model's original intention is to achieve the desired stability and "pay more, get more". However, in the actual operation process, due to China's 30 years of rapid economic growth and population aging, the system did not achieve the original intention of the original designers, the mixed model of Social pooling and Individual Retirement Account (SP\&IRA) encountered a lot of problems, especially the difficulty in achieving financial defined individual accounts [5-8]. 


\subsubsection{The current model is in lack of equity}

As per the 1997 Documents, up to 15 years contribution entitles the annual collection of basic pension of $20 \%$ of the local average wage without any incentives for contributions more than 15 years, and the basic pension has nothing to do with the salary and base pay, this has seriously affected the employees enthusiasm for long-term contribution, and directly contributed to the false reports and deliberate reduction of the wage for payments, as a consequence pension income is severely affected.

\subsubsection{Unreasonable Method for calculation of collections}

After 10 years of retirement, the pension completely rely on social pooling, with increased life expectancy and intensified ageing, the social pooling fund cannot withstand the pressure of funds, it will inevitably bring down the pension replacement rate and living standards. In 2005, the StateCouncil-promulgated Document is more scientific and reasonable for the promotion of balance of social pooling account, and the reduction of individual account's empty running. But this Document still evaded the question of the compensation of transition costs, individual accounts' empty account operation, pooling accounts' deficit and other issues still exist.

\subsubsection{Empty operation of individual account makes it difficult to implement FDC}

In the actual operation process, FDC-type individual accounts' actual operation is difficult, this is because: First, the intergenerational costs can not be resolved; second, the presence of high cost and moral hazard, after financial defined, if fully market-oriented operation model is selected, the management cost shall be very high, and once the bankruptcy of investment projects occurred, the government must pay for moral hazard. The main reasons for running empty account are as follows.

\subsubsection{Poor appreciation capacity of financial defined funds for individual accounts}

Currently a huge accumulation of individual account funds has been formed, meanwhile investment channels are severely limited, the current level of individual account funds' preservation and appreciation is, in average, about $2-3 \%$, which is far below the level of inflation. If individual accounts are financially defined and not applied to investment or consumption, the total social savings rate shall increase year by year, this will have a crowding-out effect upon investment and consumption, and aggravate the problems of reduced rate of investment in the economy, export dependence and low consumption rate etc.

\subsection{5 comparatively low social pooling levels, huge differences pension levels of different areas}

China's county-based social pooling levels are subject to the influence of regional economic development level, the population and age structure, and the types of enterprises, leading to huge differences in fund balance, such as different contribution rates, benefits standards and management systems in different regions, this has severely impaired pension insurance's mutual-aid function, and directly leads to disintegration of labor migration. At same time, a major flaw of the system is its reverse incentives defect, resulting in low levels of social pooling, local governments inevitably take advantage of social pooling to request more pensions, while detaining payment. Currently a three trillion yuan pension surplus all lies in the hands of city \& county-level. From 1991 to date, more than twenty years have elapsed since the central government proposed national social pooling, which remains in a standstill due to the refusal of provinces with surplus to subsidize those with deficits.

Therefore, under the current pension model, it is almost impossible for real operation of individual accounts, which does not comply with China's national conditions due to unavoidable financing challenges and investment bottlenecks.

\subsection{Merits of "Small Pooling, Big Accounts" model and NDC}

With its debut in 1998, NDC is the latest pension system, it is PAYG-based in financing as compared with the PAYG system and fund accumulation system accounts; in terms of calculation and collection method, it is contribution-defined, NDC account's advantage lies in that it can enhance the enrollees' personal responsibility in the pension system while avoiding the above-said financing challenges and investment bottlenecks[9,10].

\subsubsection{Help to improve the social pooling level}

Under the NDC-based SP\&IRA model, national social pooling cannot be achieved until most of the pension is deemed as personal property, which is severed from local governments. Once the social pooling problem is resolved, a lot of issues, such as investment appreciation and so forth, shall be 
readily solved, which implies the realization of centralized management $\&$ distribution of funds, and flexible investment portfolios, the fund's rate of return will be greatly enhanced, which is more conducive to the promotion of People's welfare.

\subsubsection{Help to give positive incentives to enrollees, to increase the contribution years, and achieve delayed retirement}

Since NDC is a contribution-defined model to determine the collection standard for future pensions in accordance with personal contribution accounting, combined with wage growth rate, population growth rate and other factors. Given that NDC's calculation and collection method can ensure "Pay more, get more", and endogenous growth rate can ensure that the funds will not depreciate, therefore, NDC is conducive to positive incentives to enrollees, to increase the contribution years, and achieve delayed retirement.

\subsubsection{Investment bottlenecks disappeared}

Since NDC does not accumulate funds, in a given period, the current sources of retirement funding are from concurrent employees' contribution, NDC's assets are virtual assets without capital surplus, the investment bottleneck constraints are therefore non-existent. The appreciation of its assets is realized via endogenous growth, the rate of which is comprehensively calculated as per the average wage growth rate, employment growth rate and other factors.

\subsubsection{Improve the level of pensioners' benefits or reduce contributors' contribution rates}

The mixed management of NDC funds and social pooling funds can strengthen the financial solvency, improve the pensioners' overall replacement rate, or reduce the contributors' contribution rates, and uplift their consumption level of the current period. Given that the population growth rate, wage growth rate and other factors, that affect the financial sustainability of the pension system, remain unchanged, the improvement of investment returns denotes that the contribution rate of enrollees can be appropriately reduced.

\subsubsection{Ease the pressure of current payment, and reduce the financial burden}

NDC can achieve mixed management of social pooling funds, which is conducive to effective realization of the utility of paid-in pension funds, to the National social pooling of Pension Insurance Fund, therefore it is a useful route for pension system top-level design. NDC funds are partly or fully allocated to individual accounts of contributors' individual accounts, or appropriated in full to social pooling, thereby it can be used to improve the system's ability to pay, reduce the financial burden or the economic expenditure of the future contributors. Mixed management of funds can, on the one hand, revitalize the dormant individual accounts fund, on the other hand, enable flexible investment of this fund by qualified social security fund management institutions via the supporting National Social Security Fund Management Mechanism, to achieve capital preservation and appreciation.

Of course, such investment income is unstable, but this volatility can be resolved by the following supporting systems: First, the "risk reserve system," i.e., pension fund investment operators can extract capital from the risk reserve to prepare for contingencies; second, the establishment of a market-oriented guarantee system, wherein operators purchase the "commercial re-insurance scheme"; third, the establishment of a Policy-mandated re-insurance system, namely the establishment of a "Central Security Company."

At the same time, this hybrid SP\&IRA model can better save system transformation cost, pension fund in this management system can be used to for intergenerational payment, which reduces the state financial subsidies for the conversion process, saving the state financial expenditure.

\section{Conclusion}

Essentially, the contributor's rights and interests shall remain unchanged, be it financially defined or not, in NDC or otherwise. For insured employees of the enterprises, since arbitrary withdrawal from individual accounts is not viable, no substantial impact shall be placed upon pension payments for employees. The "Decision of the Central Committee of the Communist Party of China on Major Issues Concerning Comprehensively Deepening Reforms" also explicitly purports to improve the 
system of individual accounts rather than financially define them, this is a positive signal for individual accounts reforms.

In short, as compared with the other two accounts on equal terms, NDC can achieve higher pension replacement rate, total value and connotative ROR with fewer risks and less government investment; NDC is more conducive to system management, and enhancement of equity. The individual accounts of China's current pension system is difficult to be financially defined, with empty account operation, it is in effect a "Dissimilated Type" of NDC without "NDC" advantages. Thereby the following conclusion is drawn: the hybrid SP\&IPA model based on NDC funding model is a rational choice suitable for China's pension reform, it is conducive to the realization of welfare of the people and national interests.

\section{Acknowledgment}

This research was supported by the NSFC(No: 71473073) and project from Hubei provincial Department of Education ( No:2012D036), Natural Science Foundation of Hubei Province of China(2015CFB708), and Educational Commission of Hubei Province of China(D20152801).

\section{References}

[1] Wang Yanzhong, Wang Junxia. The study of individual account system in China's public old-age insurance system. Social Security Research, 2012, 4: 94- 99.

[2] Holzmann, R., Palmer, E., Robalino, D. Nonfinancial Defined Contribution Pension Schemes in a Changing Pension World:Gender, Politics, and Financial Stability (Vol. 2) [M]. Washington, D. C.: The World Bank, 2012.

[3] Zheng Bingwen. China Pension Report 2013. Economic Management Publishing House, 2013 edition

[4] Ma Zhongdong, Lv Zhihao, Ye Kongjia. Labor force participation rate and labor force growth: from 1982 to 2050 [J]. Beijing: China Population Science, 2010, (1).

[5]Xiong Xihong. Research on model selection and Financial Sustainable Development of China's urban employees' Pension Insurance Model Reform. CASS doctoral thesis, 2014.

[6] OECD. "Pensions at a Glance 2011: Retirement-income Systems in OECD and G20 Countries", 2011, p.21-26.

[7]Wang Xinmei. Global reform of public pension insurance system and China's choices GDP-related NDC is more reliable and preferable than capital-market-related FDC. World Economic Papers, 2005, 6:56 75, 79 .

[8] Ding Jianding, Guo Lin.NDCcontribution system of basic pension for employees in China: actuarial model and quantitative analysis. Social Security Research, 2012,16 (2): 80-90.

[9] Cheng Huan, Lin Yi. Exploration on the Path of system optimization in the mixed model of social pooling-- individual account under population aging. Social Security Research, 2013,2: 56-69.

[10] Wang Xiaojun, Mi Haijie. An empirical analysis on individual account model selection for Chinese social pension. Economic Management, 2013, 6:164-173. 